\title{
PREDIKSI SPRINGBACK PADA PROSES DEEP DRAWING DENGAN PELAT JENIS TAILORED BLANK MENGGUNAKAN PERANGKAT LUNAK BERBASIS METODE ELEMEN HINGGA
}

\author{
Tri Widodo Besar Riyadi, Alfian Safaat, Bambang Waluyo Febriantoko \\ Teknik Mesin Universitas Muhammadiyah Surakarta \\ Jl. A. Yani Tromol Pos 1 Pabelan, Kartasura \\ Email :tri.riyadi@ums.ac.id
}

\begin{abstract}
ABSTRAK
Tujuan yang ingin didapat dari simulasi ini yaitu mengetahui terjadinya fenomena springback dan "weld movement" pada proses deep drawing khususnya pada pelat jenis tailored blank sehingga dapat dilakukan permodelan desain deep drawing untuk optimasi hasil draw piece agar springback bukan menjadi masalah dalam proses deep drawing.

Pada simulasi ini, model yang digunakan adalah square cup deep drawing dengan dimensi model dies, diameter atas $d 1: 180 \mathrm{~mm}$, diameter tengah $d 2: 80 \mathrm{~mm}$, diameter bawah d $3: 60 \mathrm{~mm}$, kedalaman atas $\mathrm{h} 1: 10 \mathrm{~mm}$, kedalaman tengah $\mathrm{h} 2: 10 \mathrm{~mm}$ dengan radius 1350 , dan kedalaman bawah h3:10 mm. Bahan tailored welded blanks (TWB) yang digunakan yaitu pelat baja (mild steel) dengan ketebalan $1 \mathrm{~mm}$ dan 0,8 $\mathrm{mm}$ kemudian di las. Diameter benda uji (blank) yang digunakan yaitu: $160 \mathrm{~mm}$.

Hasil simulasi pada kedua pelat tebal dan pelat tipis, menunjukkan kecenderungan yang sama, yaitu bahwa springback terbesar terjadi pada bagian penampang samping, sedangkan springback terkecil terjadi pada bagian bawah. Sedangkan Pergerakan lajur las (weld movement) mengalir dari pelat dengan ketebalan $1 \mathrm{~mm}$ menuju ketebalan 0,8 mm, hal ini terjadi karena tegangan mengalir menuju pada pelat yang lebih tipis
\end{abstract}

Kata kunci: Tailored Blank, Springback, Weld Movement.

\section{PENDAHULUAN}

Perkembangan teknologi perangkat keras komputer telah memungkinkan dilakukannya simulasi proses pembentukan material (material forming) dengan murah dan dalam skala waktu yang memadai. Berbagai proses pembentukan material dari material lembaran (sheet forming) telah berhasil dilakukan dengan cukup memuaskan. Keberhasilan untuk pembentukan material lembaran ini juga telah mendorong penerapan metode yang berbasis komputasi numerik untuk diterapkan pada kasus pembentukan material, seperti proses deep drawing, forging, casting, dan extrusion.

Salah satu bagian pada proses metal forming adalah deep drawing. Proses deep drawing adalah proses pembentukan material steel sheet / blank mengikuti dies, dimana material steel sheet / blank dijepit dan dipasang pada blank holder dan dies yang selanjutnya dengan bantuan mesin press dilakukan penekanan, bentuk akhir ditentukan oleh punch sebagai penekan dan dies sebagai penahan benda kerja saat ditekan oleh punch, sehingga terbentuk komponen yang kita inginkan [1].

Pada prakteknya di industri, desain cetakan dan pemilihan suatu rute proses pembentukan deep drawing masih banyak bergantung kepada cara trial - error yang tidak efisien baik dari 
segi waktu dan biaya. Pengembangan metoda komputasi numerik berbasis metode elemen hingga merupakan salah satu alternatif untuk mempercepat proses optimisasi proses deep drawing. Penggunaan teknik pemodelan elemen hingga untuk proses deep drawing dapat melakukan prediksi berbagai parameter proses yang terlibat, seperti pola aliran material pada cetakan, distribusi tegangan dan temperatur pada benda kerja, kemungkinan terjadinya cacat dan juga prediksi sifat mekanis dari produk deep drawing yang diperoleh. Di samping itu, dapat juga dihitung tekanan yang terjadi pada peralatan pembentuk (tooling), sehingga dapat diprediksi kemungkinan terjadinya fraktur pada cetakan [1].

Keberhasilan penggunaan teknik pemodelan proses deep drawing di industri terutama ditentukan oleh ketentuan-ketentuan : perangkat lunak yang akurat, cepat dan handal dalam memodelkan berbagai parameter kunci dalam deep drawing seperti friksi antara material yang dibentuk dengan cetakan, interface yang mudah antara pemakai dengan perangkat lunak, hasil simulasi yang berupa pola alir dari material yang memadai untuk evaluasi proses deep drawing dan sifat mekanis produk, ketersediaan tenaga ahli dalam melakukan pelatihan dan adaptasi untuk penggunaan di industri [1].

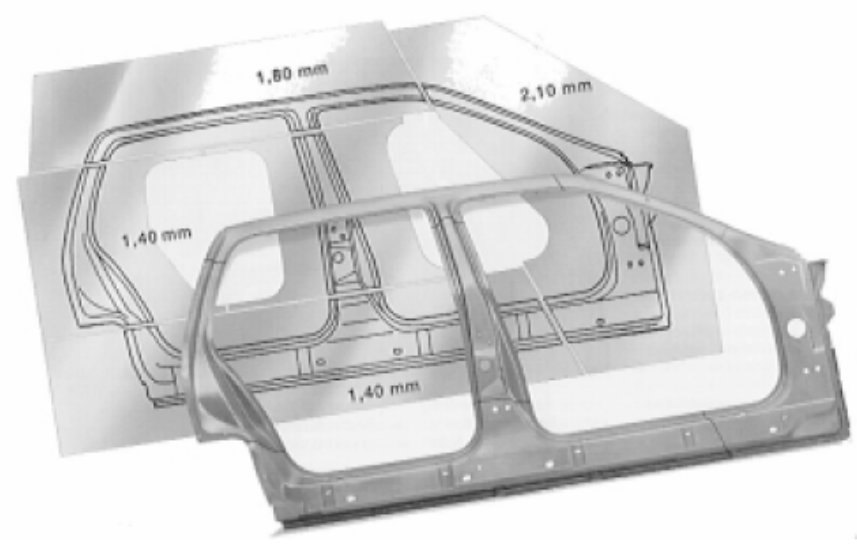

Gambar 1. Hasil Proses Deep Drawing [2]

Dalam menganalisa cacat pada produk hasil deep drawing saat ini masih menggunakan cara konvensional, dimana cara ini masih mengandalkan pengalaman dan keahlian dalam menganalisa kecacatan produk dengan menggunakan metode trial and error. Analisis statis menunjukan bahwa kekuatan dan ketebalan benda adalah parameter yang paling dominan, diikuti oleh draw ratio, punch-die clearance [3].

Sifat semua material yang mempunyai suatu modulus elastisitas terbatas menyebabkan deformasi plastis akan diikuti oleh sifat elastis material. Pada saat bending dihilangkan akan terjadi perubahan bentuk atau penyimpangan terhadap permukaan die yang digunakan untuk penekanan, hal ini disebabkan karena plat memiliki sifat elastis sehingga sebagian deformasi akan sedikit kembali ke titik tertentu. Penyimpangan bentuk dan ukuran karena sifat elastisitas bahan ini dikenal dengan istilah springback. Springback tidak hanya terjadi pada plat tipis atau plat datar, tetapi juga terjadi pada bentuk poros pejal, kawat, batang dengan luas area tertentu, serta pada pipa. Pada prakteknya springback dapat dikurangi dengan cara overbending, yaitu sudut pembengkokan lebih kecil daripada yang diperlukan.

Blank yang digunakan dalam proses deep drawing juga ada yang menggunakan blank dengan ketebalan berbeda, blank ini biasa disebut Tailored Welded Blanks (TWB), yaitu menggambungkan dari dua macam atau lebih lembaran metal dengan ketebalan (thickness) berbeda yang disambung menggunakan las. Setelah tailored welded blanks (TWB) mengalami deformasi atau ketika punch menekan blank, maka garis sambungan(weld line) juga akan 
mengalami pergeseran, istilah ini disebut juga dengan weld movement. Dalam proses deep drawing sangat identik dengan terjadinya springback, maka perumusan masalah pada penelitian ini adalah mengidentifikasi springback yang terjadi pada proses deep drawing, sehingga produk yang dihasilkan sesuai dengan rencana.

\section{METODE PENELITIAN}

Analis pada penelitian ini menggunakan software ABAQUS. Program ABAQUS bekerja berdasarkan teori dasar yang dikembangkan pada Metode Elemen Hingga (MEH) yang kemudian ditransfer kedalam bahasa program menggunakan bahasa FORTRAN dan $\mathrm{C}++$ agar bisa dibaca oleh perangkat lunak. Software ABAQUS menyediakan program yang digunakan untuk memodelkan benda yang akan dianalisis yang diberi nama ABAQUS CAE. Program ini berfungsi sebagai desain model yang akan kita analisa kekuatannya. Seperti kebanyakan program komputer yang banyak tersedia dipasaran, ABAQUS mempunyai fasilitas CAD/CAM/CAE yang bisa difungsikan sebagai program analisa elastis dan plastis [4] ABAQUS Theory Manual, 2003.

\section{Preprocessing ( ABAQUS CAE )}

Pemodelan dilakukan di dalam ABAQUS CAE dengan memasukkan geometri yang telah kita lakukan pengukuran sebelumnya atau dari data yang telah kita import dari input file.

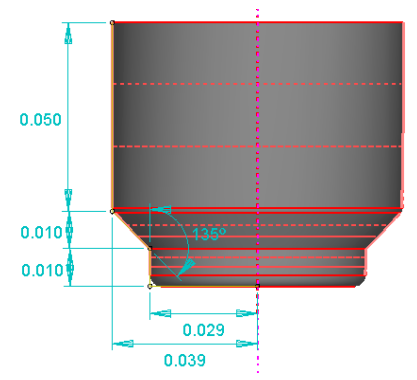

(a)

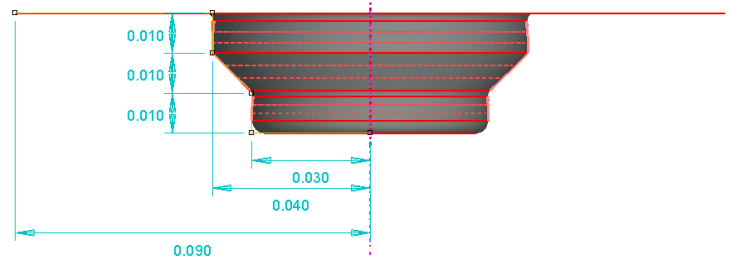

(b)

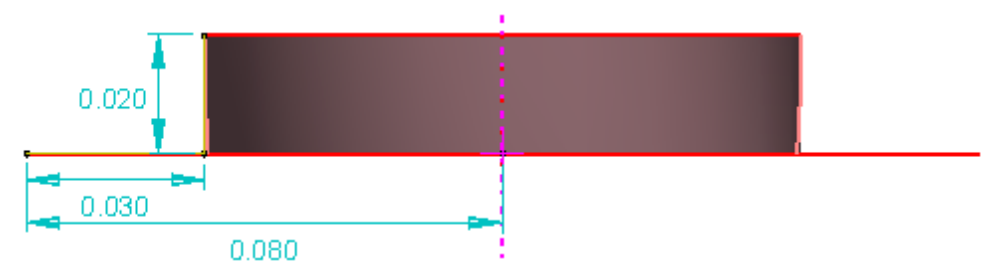

(c)

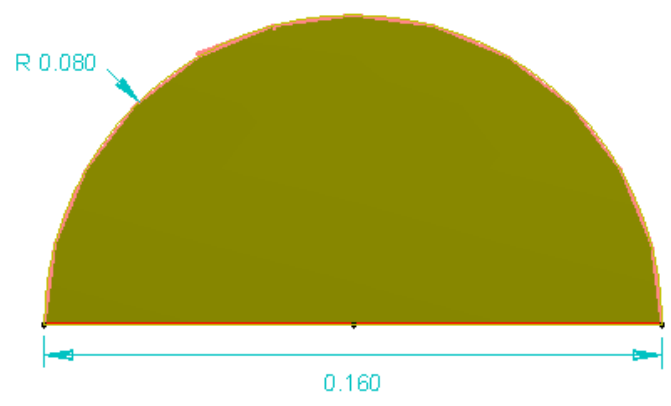

(d)

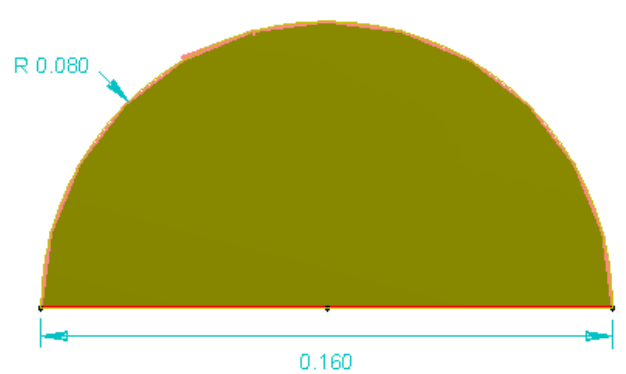

(e)

Gambar 2. (a) Sket Punch, (b) Sket Die, (c) Sket Blank Holder, (d) Sket Blank Tebal dan (e) Sket Blank Tipis 


\section{Simulasi (ABAQUS Standard dan ABAQUS Explicit )}

ABAQUS Standard dan ABAQUS Explicit digunakan untuk melakukan simulasi dari hasil prosesing didalam software ABAQUS. Pada tingkat ini ABAQUS memecahkan permasalahan yang diberikan kedalam program dengan melakukan penyelesaian secara numerik. Sebagai contohnya keluaran dari analisa tegangan yang meliputi perpindahan dan tegangan yang disimpan dalam file binary siap untuk post processing. Tergantung dari kerumitan masalah yang di analisa dan kemampuan komputer yang digunakan, ini bisa dilihat dari running yang dilakukan bisa dalam beberapa detik atau berhari-hari.

\section{Post Processing ( ABAQUS CAE )}

Kita bisa mengevaluasi hasil dari simulasi yang telah lengkap dan perpindahan, tegangan atau variabel fundamental lain yang telah selesai dihitung. Evaluasi biasanya dilakukan secara interaktif menggunakan visualisasi modul dari ABAQUS/CAE atau postprocessor yang lain. Modul visualisasi, yang membaca binary file output database, mempunyai bermacam - macam pilihan untuk ditampilkan meliputi plot kontur warna, animasi, plot perubahan bentuk dan plot grafik X-Y.

\section{HASIL PENELITIAN DAN PEMBAHASAN \\ Visualisasi Proses Tailored Blanks Deep Drawing}

Simulasi penelitian yang dilakukan adalah proses deep drawing dengan pelat jenis tailored blank yang terdiri dari dua pelat dengan ketebalan berbeda yaitu $0,8 \mathrm{~mm}$ dan 1,0 $\mathrm{mm}$, tapi dari material yang sama yaitu mild steel yang merupakan material elastis plastis. Pelat berbentuk lingkaran yang terbagi menjadi dua bagian yang sama dan disambung dengan las pada bagian tengahnya, yang biasanya dilakukan dengan laser. Visualisasi proses deep drawing menggunakan plat jenis tailored blank dengan ABAQUS terlihat seperti pada gambar 3 .

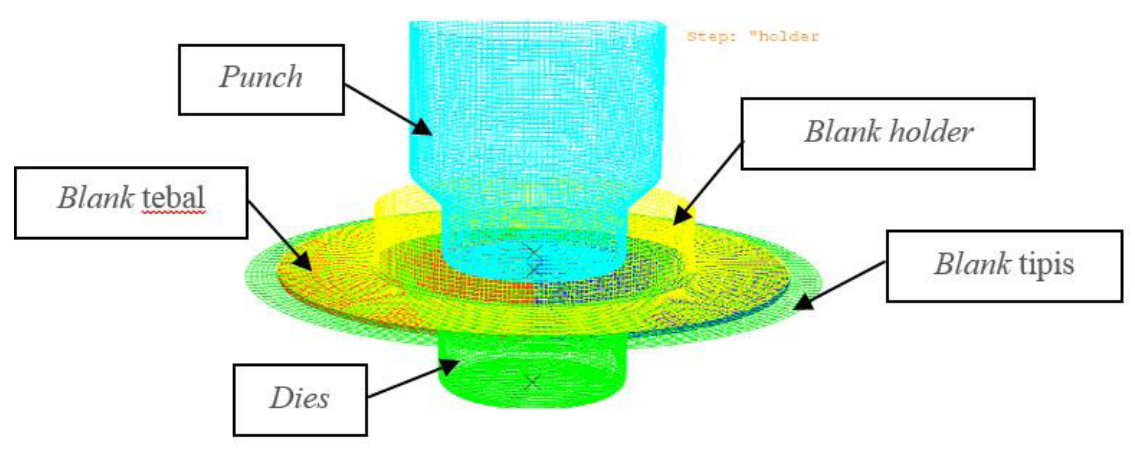

(a)

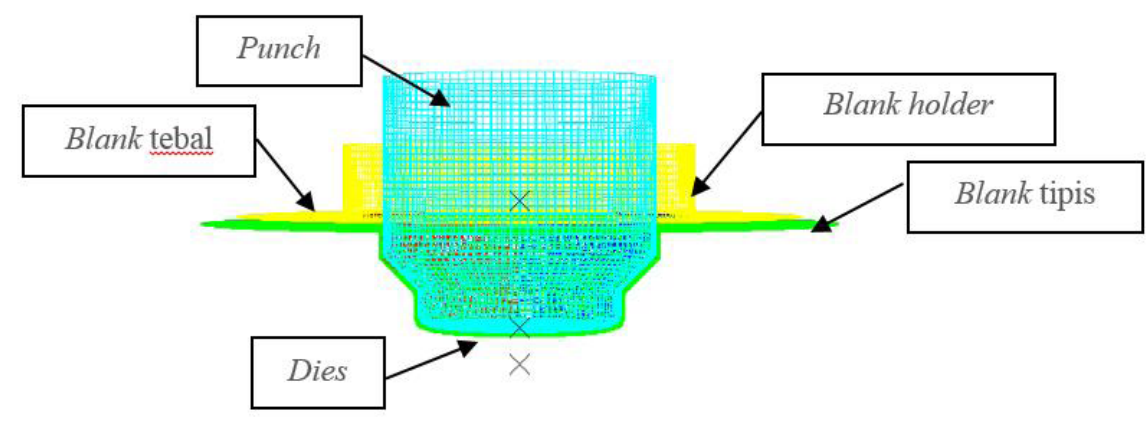

(b)

Gambar 3. (a) Kondisi awal proses deep drawing, (b) Proses deep drawing saat punch telah bergerak ke bawah (forming) 


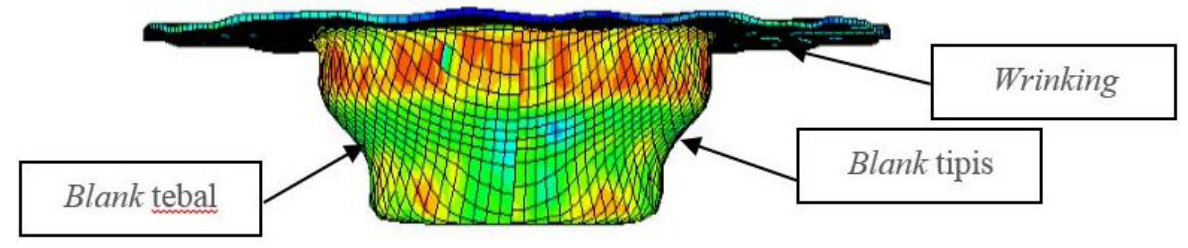

Gambar 4. Hasil proses deep drawing.

Dari hasil simulasi deep drawing di atas dapat dijelaskan bahwa bagian yang paling besar meregangnya adalah pada bagian dinding yang tidak bersentuhan dengan dies. Dari hasil pengujian diketahui bahwa weld movement (gerakan las) pada bagian sisa cup bergerak ke arah pelat dengan ketebalan $0,8 \mathrm{~mm}$. Hal ini terjadi karena tegangan tekan mengalir pada plat yang lebih tipis.

Secara umum, deep drawing adalah proses dimana pelat (blank) dipaksa mengalir melalui sebuah dies dengan beban punch sehingga membentuk komponen silindris. Selama proses deep drawing, pelat ditekan dengan gaya penekan yang berasal dari mesin penekan sampai mencapai nilai maksimumnya pada TMA. Material akan mengalami regangan yang cukup besar sepanjang diameternya. Bagian yang paling besar meregangnya adalah pada bagian dinding yang tidak bersentuhan dengan dies. Pada bagian ini pelat akan mengalami penipisan atau ironing. Penipisan dapat menjadikan pelat mengalami retak dan kemudian pecah setelah mencapai kekuatan tarik maksimum pelat. Bagian yang paling kritis dimana sering terjadi pecah adalah pada bagian bawah yang bersentuhan dengan radius punch. Pada bagian ini sering terjadi pecah karena tekanan bending yang sangat besar tergantung dari radius punch.

\section{Grafik Gaya Punch terhadap waktu penekanan}

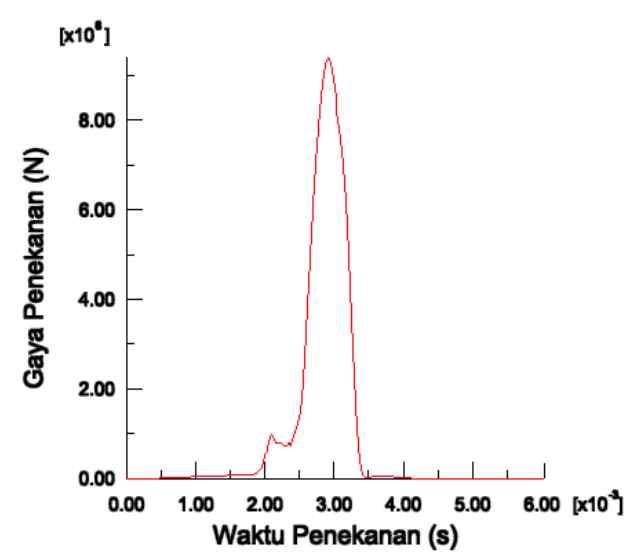

Gambar 5. Gaya Penekanan vs Waktu Penekan Tailored Blank

Gambar 5 menunjukkan grafik hasil gaya penekanan yang diberikan oleh punch terhadap waktu penekanan ketika terjadi proses deep drawing. Hasil simulasi tailored blanks deep drawing memberikan keterangan bahwa gaya punch mengalami dua kali nilai maksimal yaitu ketika mencapai jarak $2,2 \mathrm{~mm}$, gaya punch mencapai $12 \mathrm{KN}$, kemudian gaya akan turun sampai sekitar $8 \mathrm{KN}$ dan kemudian naik lagi sampai nilai maksimum yang kedua yaitu 94 KN. Fenomena dua kali mencapai puncak dalam proses deep drawing disini kemungkinan dapat diakibatkan oleh proses penekanan pelat yang mengalami dua tahap, yang menghasilkan dua proses tekuk (bending).

Untuk mengetahui perbandingan antara pelat gabungan terhadap pelat homogen, 
gambar 6 berikut menyajikan perbandingan gaya penekanan versus waktu penekanan uniformed blank (blank tebal saja dan blank tipis saja). Dari gambar tersebut dapat diketahui bahwa besar gaya penekanan material tailored blank terletak diantara gaya penekanan pelat homogen yang tipis saja dan yang tebal saja. Hasil ini menunjukan bahwa pengaruh las telah diabaikan sehingga tidak mempengaruhi besar gaya penekanan. Penelitian lanjutan dapat dilakukan untuk mengetahui dan menganalisis pengaruh kekuatan las terhadap gaya penekanan.

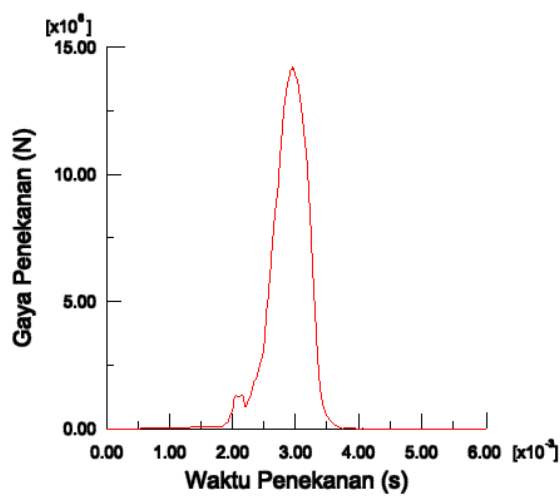

(a)

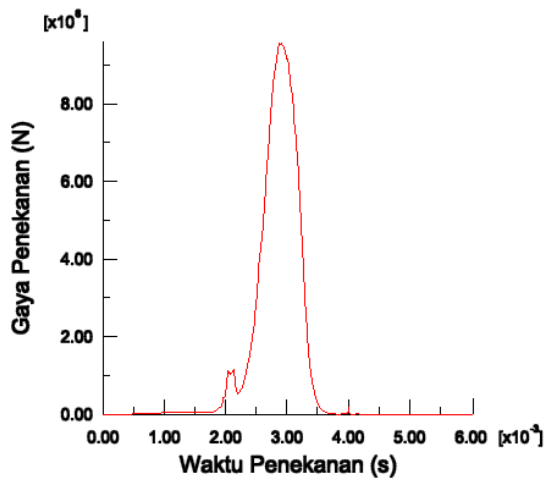

(b)

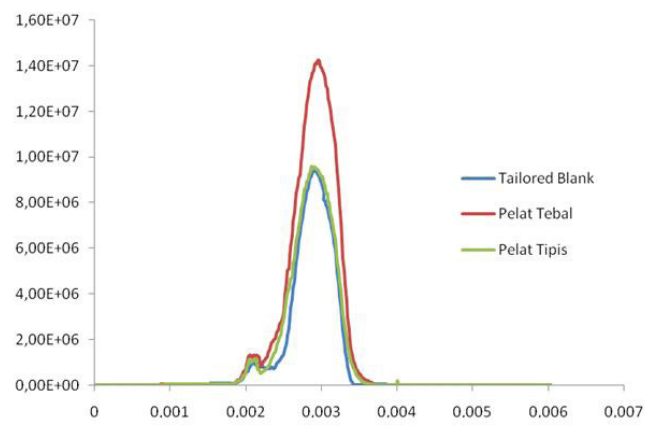

(c)

Gambar 6. (a) Gaya Penekan vs Waktu Penekanan Pelat tebal, (b) Gaya penekanan vs waktu penekanan pelat tipis, (c) Grafik Gabungan Tiga Pelat

\section{Analisis springback pada pelat tebal dan pelat tipis}

Pengukuran springback dilakukan terhadap pergerakan node yang ada di tengahtengah pelat tebal dan pelat tipis, melintang terhadap arah sambungan. Untuk mengetahui springback maka pengukuran node-node tersebut dilakukan pada langkah sebelum punch diangkat dan setelah punch diangkat. Hal ini untuk mengetahui pengaruh sifat elastis material ketika mendapat beban (load) dan ketika beban tersebut dilepaskan (unload). Pengukuran springback disini dilakukan hanya pada sebagian pelat saja mengingat bentuk produk yang simetris. Untuk mempermudah memahami bentuk produk di sini maka sketsa dies ditampilkan lagi di gambar 7 . 


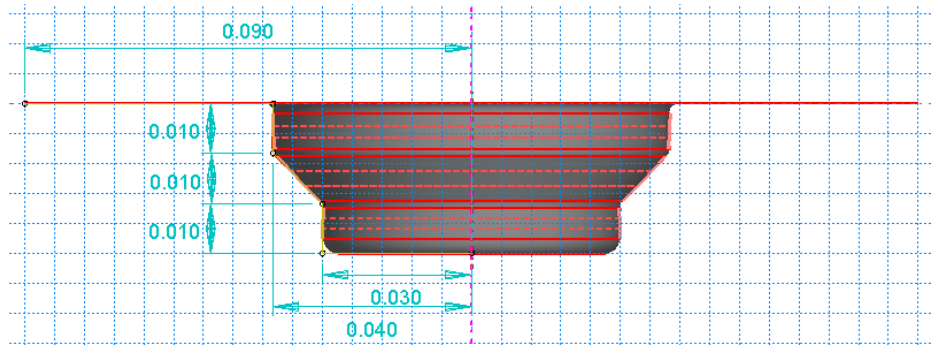

Gambar 7. Dimensi pelat dan dies

Hasil simulasi springback dapat dilihat pada gambar $8-11$ berikut ini. Garis pertama menunjukan pergerakan (penampang) pelat sebelum beban punch diangkat, dan garis kedua menunjukan pergerakan (penampang) pelat setelah beban punch diangkat. Karena pada tailored blank terdapat dua bagian pelat, maka disini ditampilkan dua hasil springback yang terjadi masing-masing pada pelat tebal dan pelat tipis. Untuk mengetahui besaran springback lebih detail, maka dibuatkan grafik tersendiri terhadap selisih antara node-node pada pelat sebelum beban diangkat dan setelah beban diangkat.

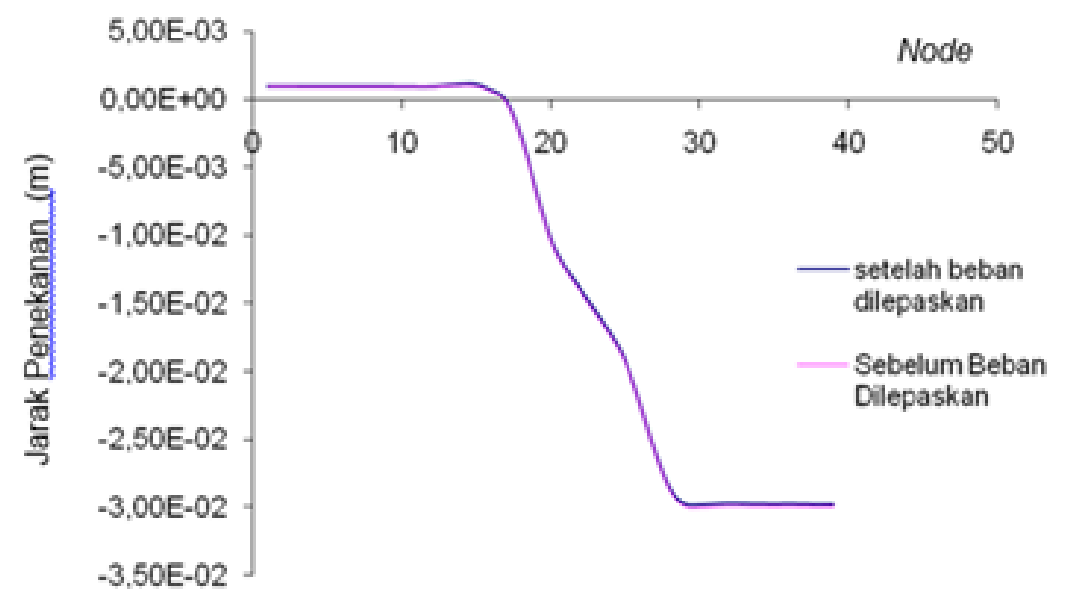

Gambar 8. Pergerakan pelat tebal sebelum dan setelah beban dilepaskan.

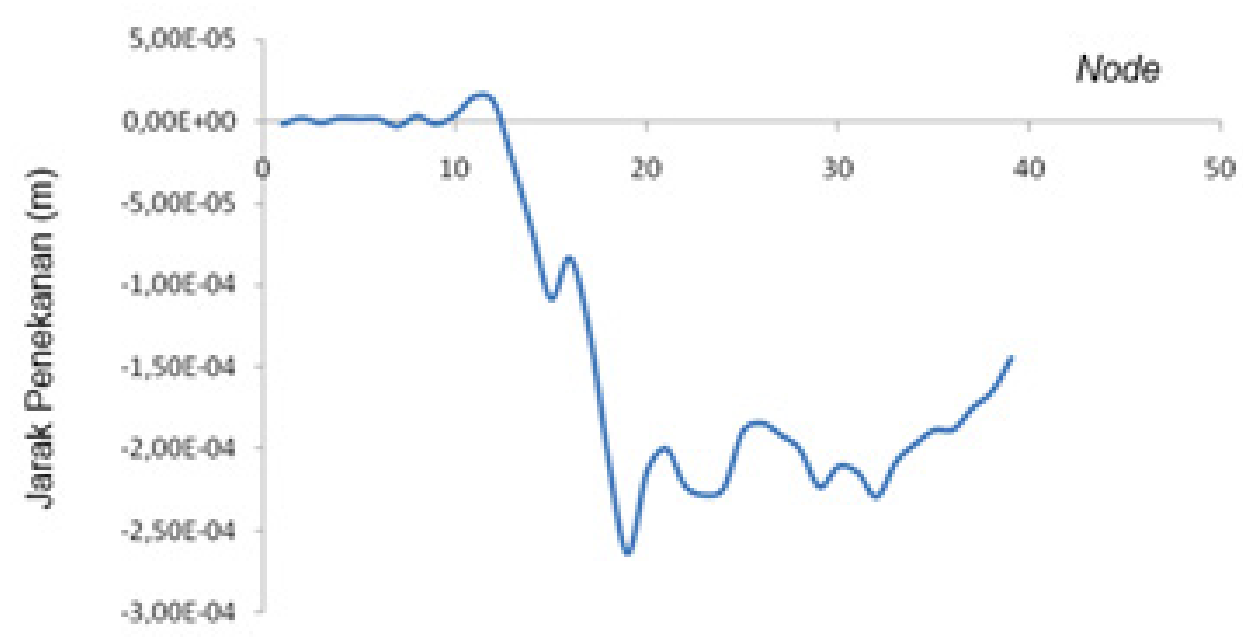

Gambar 9. Besaran springback pada pelat tebal 
ISSN: 1411-4348

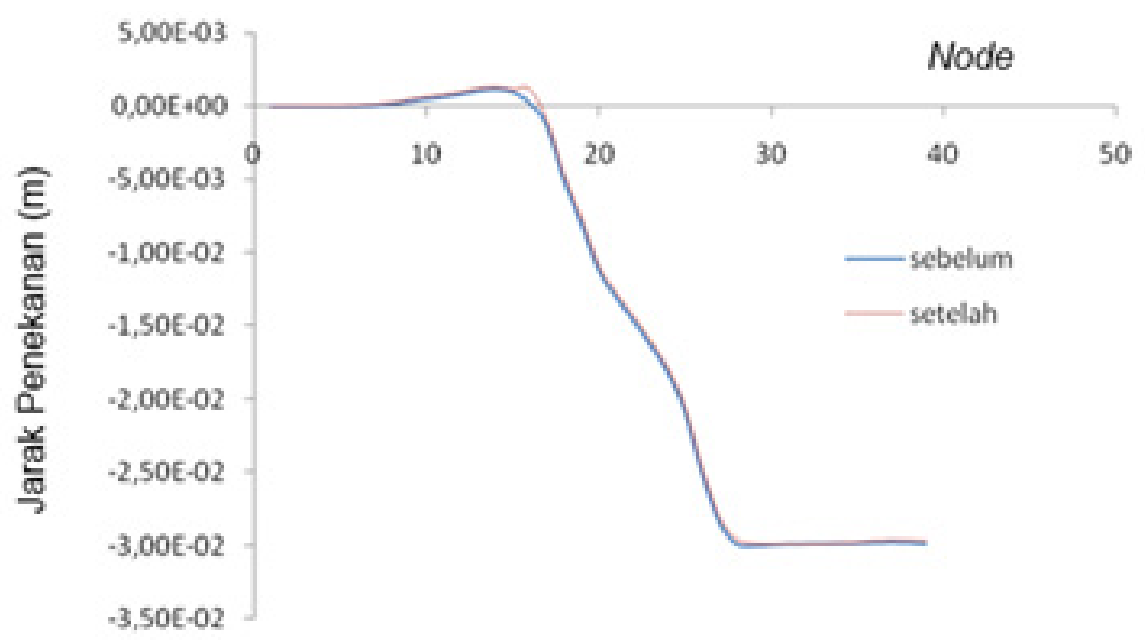

Gambar 10. Pergerkan pelat tipis sebelum dan setelah beban dilepaskan.

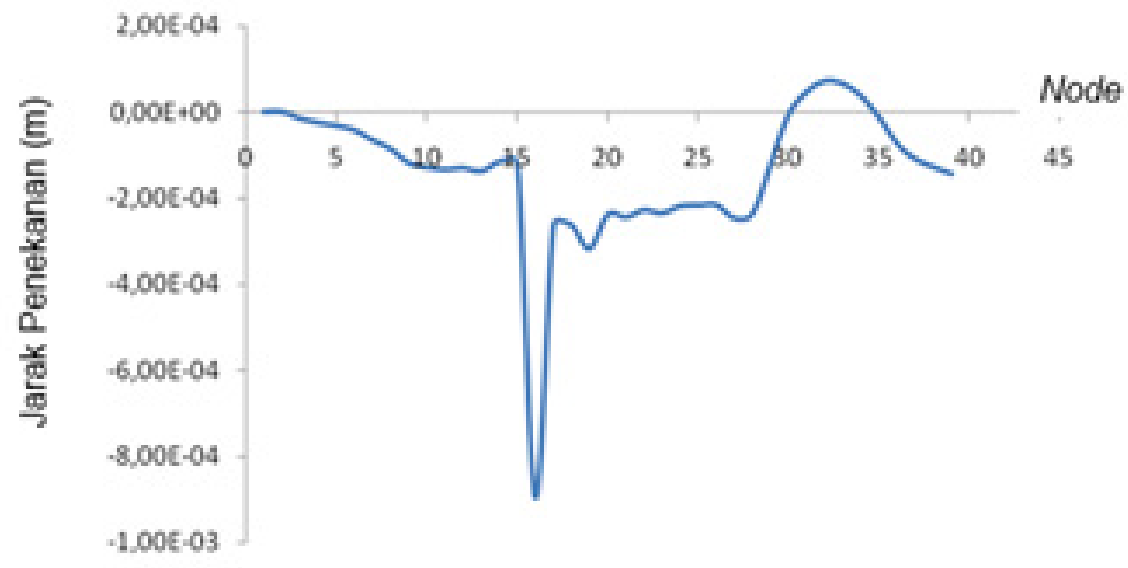

Gambar 11. Besaran springback pada pelat tipis

Untuk mengetahui lebih detail fenomena springback pada pelat tailored blank, maka dilakukan perbandingan springback yang terjadi pada pelat tipis dan pelat tebal secara terpisah. Hasil perbandingannya dapat dilihat pada gambar di bawah ini.

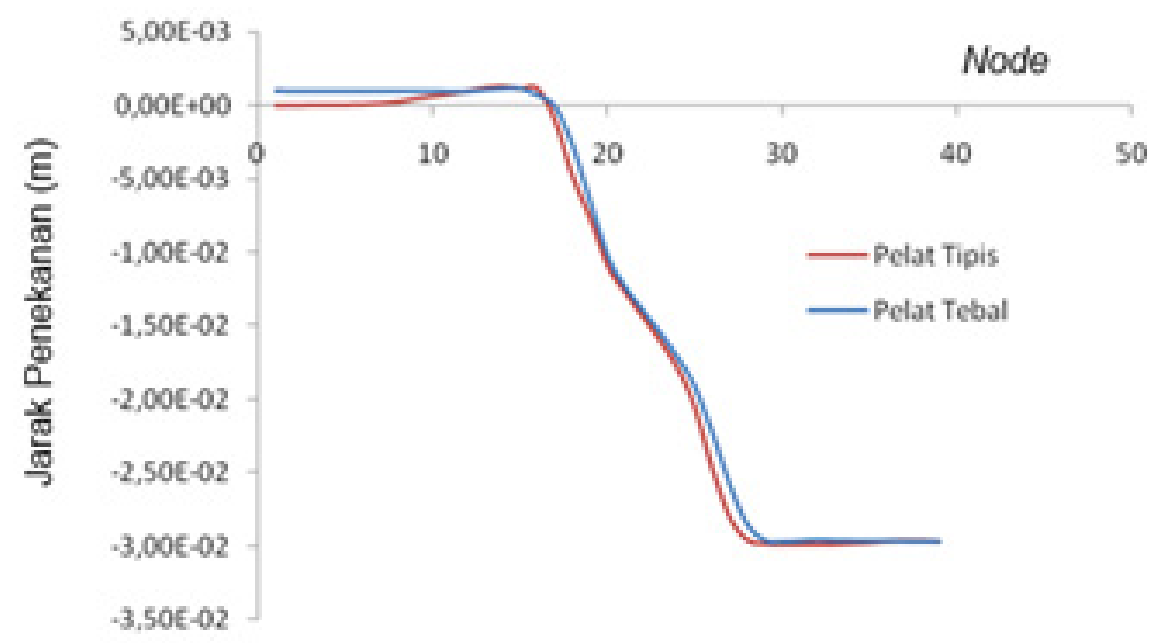

Gambar 12. Perbandingan pelat tipis dan pelat tebal setelah beban dilepaskan 


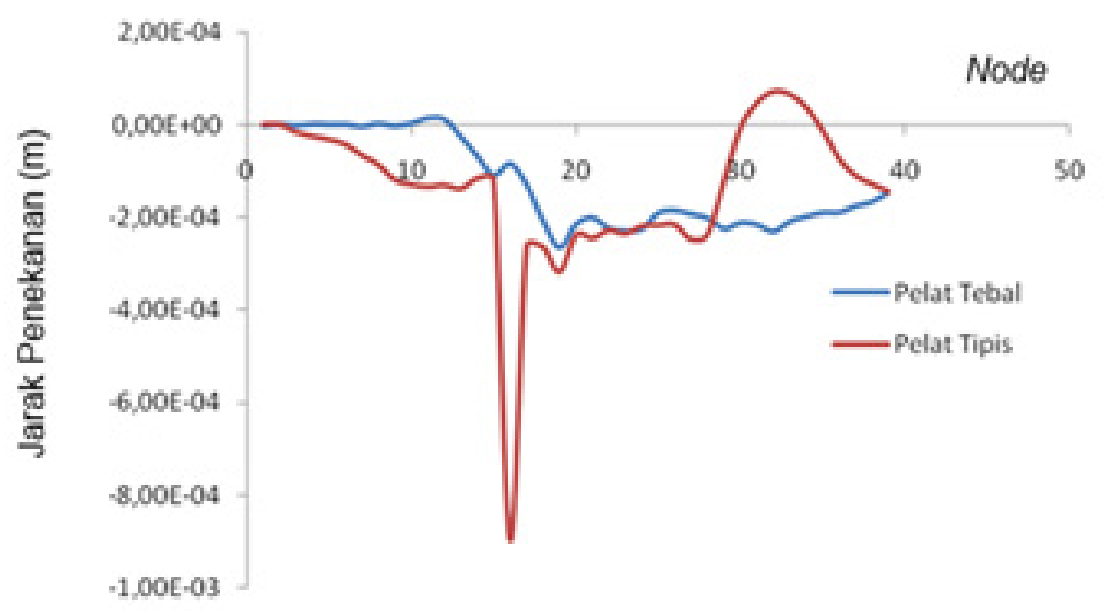

Gambar 13. Perbandingan besaran springback pada pelat tebal dan pelat tipis

Pada kedua pelat tebal dan pelat tipis tersebut, hasil simulasi menunjukan kecenderungan yang sama, yaitu bahwa springback terbesar terjadi pada bagian penampang samping, sedangkan springback terkecil terjadi pada bagian bawah. Agar hasil deep drawing sesuai hasil yang diinginkan maka desain dan ukuran dies harus disesuaikan dengan springback yang terjadi.

\section{Distribusi regangan pada Tailored Blanks sebelum dan setelah proses penekanan}
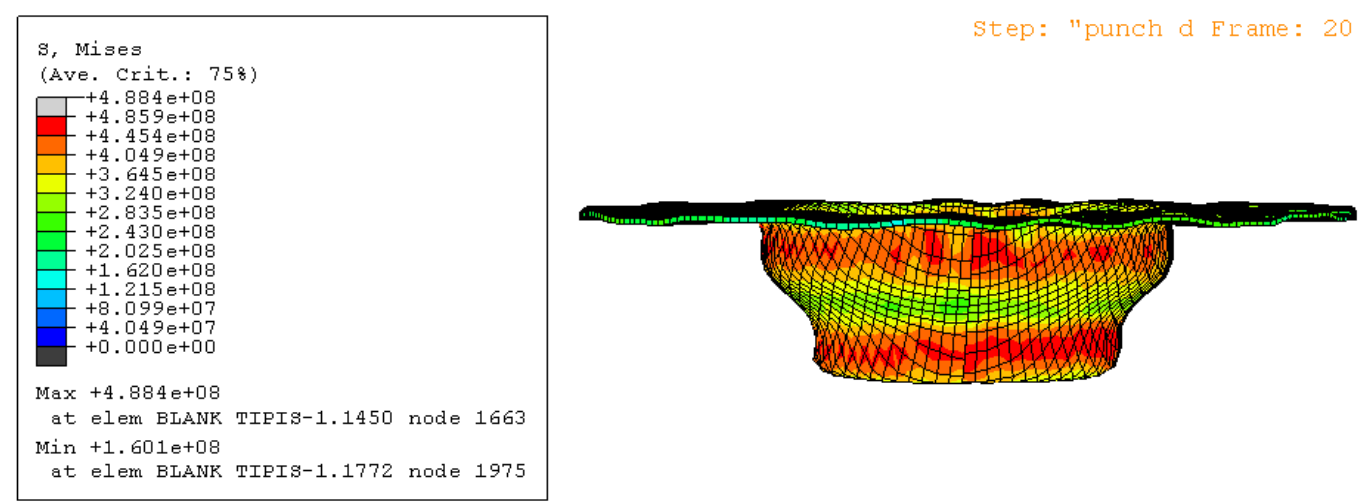

Gambar 14. Visualisasi pada blank sebelum gaya dihilangkan.

Gambar 14 menunjukkan visualisasi tegangan rata-rata yang terjadi pada tailored blanks dengan steel, frame ke 20, step time 3.00 x 10-3 second. Pada frame ini menunjukkan visualisasi distribusi tegangan pada seluruh pelat setelah mengalami proses deep drawing. Tegangan tertinggi terjadi pada daerah dinding, yang mengalami gaya penarikan yang terbesar. Pada gambar di atas ditunjukan tegangan maksimum 4,884 x 108 Pa yang terjadi pada blank tebal dengan nomor elemen 1450 nodal 1663, sedangkan tegangan minimum 1,601 x 108 Pa juga terjadi pada blank tebal dengan nomor elemen 1772, nodal 1975. 

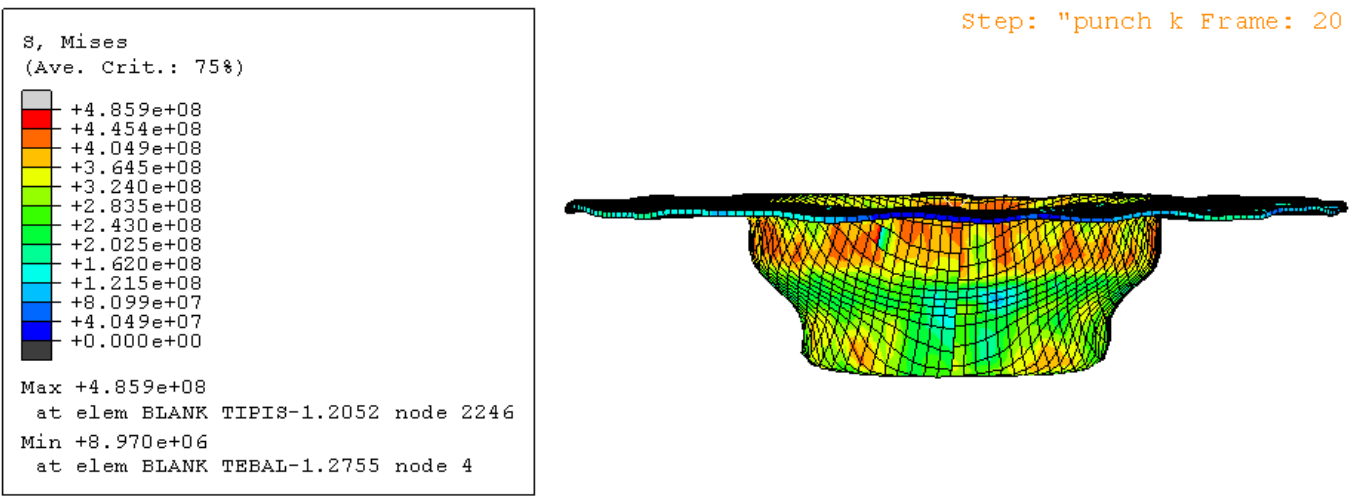

Gambar 15. Visualisasi pada tegangan pada blank setelah gaya dihilangkan.

Gambar 15 menunjukkan visualisasi distribusi tegangan yang terjadi setelah gaya punch pada proses deep drawing dihilangkan pada step springback, frame ke 20, step time 3.00E03 second.. Disini tegangan elastis pada draw piece memungkinkan terjadinya springback. Pada frame ini tegangan maksimum yang terjadi sebesar 4,859 x $108 \mathrm{~Pa}$ yang terjadi pada blank tipis dengan elemen nomor 2052 nodal 2246, sedangkan tegangan minimum 8,970 x $106 \mathrm{~Pa}$ terjadi pada blank tebal dengan elemen nomor 2755 nodal 4. Setelah punch ditarik keatas atau gaya punch dihilangkan maka akan terjadi gaya balik (springback) pada blank deformable.

\section{Pergerakan las (welding displacement)}

Selain terjadinya springback, proses deep drawing tailored blank juga menyebabkan terjadinya pergerakan dari lajur las yang sangat mempengaruhi tingkat ketepatan ukuran dari hasil deep drawing. Maka dari itu penandaan arah lajur las perlu dilakukan. Berdasarkan dari hasil simulasi dapat diketahui pergerakan las (Welding displacement) dari tailored welded blanks.

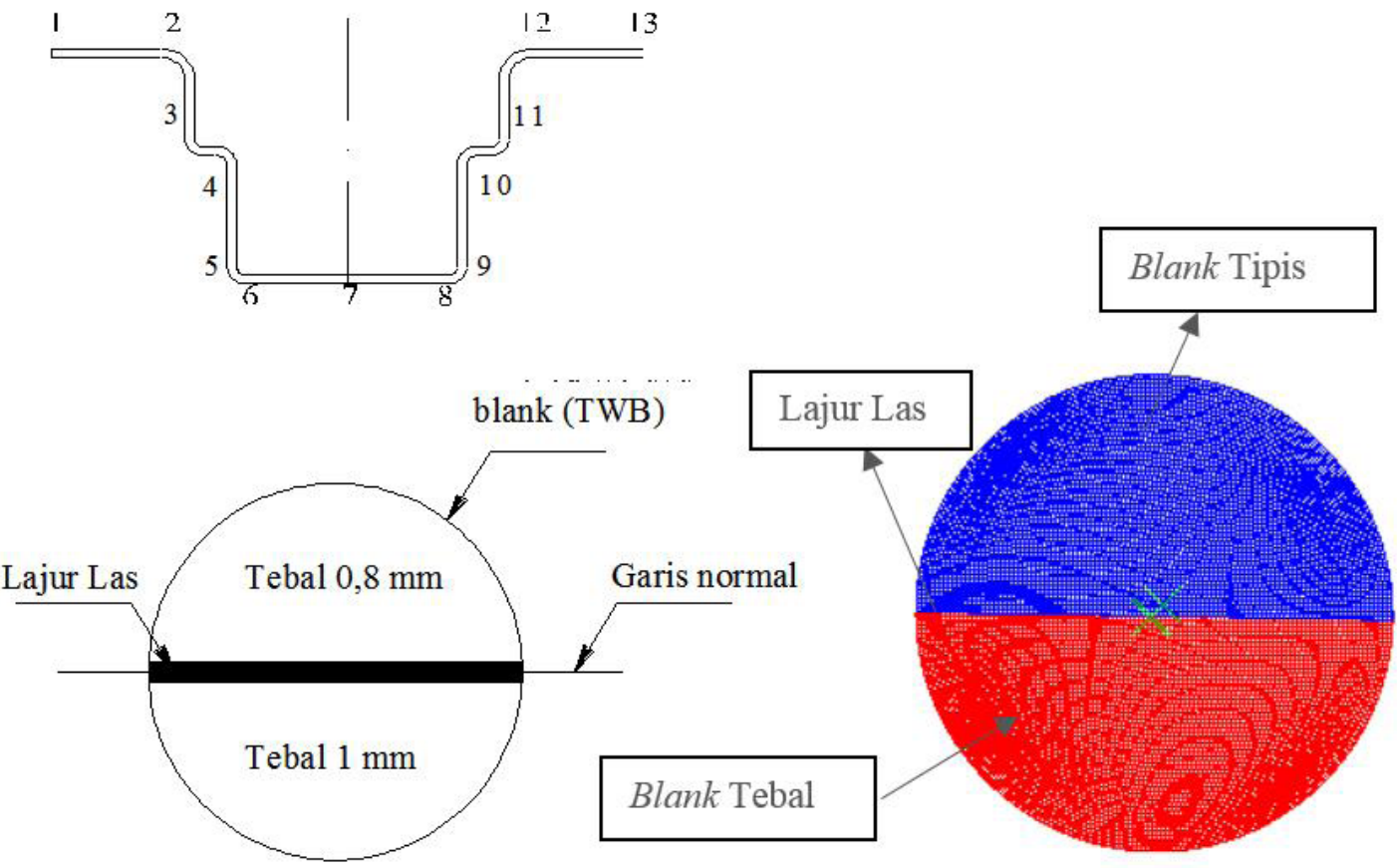

Gambar 16. Sketsa Pengukuran welding displacement pada Tailored welded blanks (TWB) 
Metode Pengukuran yang digunakan yaitu dengan cara mengukur jarak lajur las dari garis normal. Harga minus (-) menunjukkan bahwa welding displacement menuju pada ketebalan 0,8 $\mathrm{mm}$. Dari hasil pengukuran, dapat diketahui bahwa arah pergerakan lajur las menuju pada ketebalan $0,8 \mathrm{~mm}$. Hal ini terjadi karena tegangan mengalir menuju pada plat yang lebih tipis.

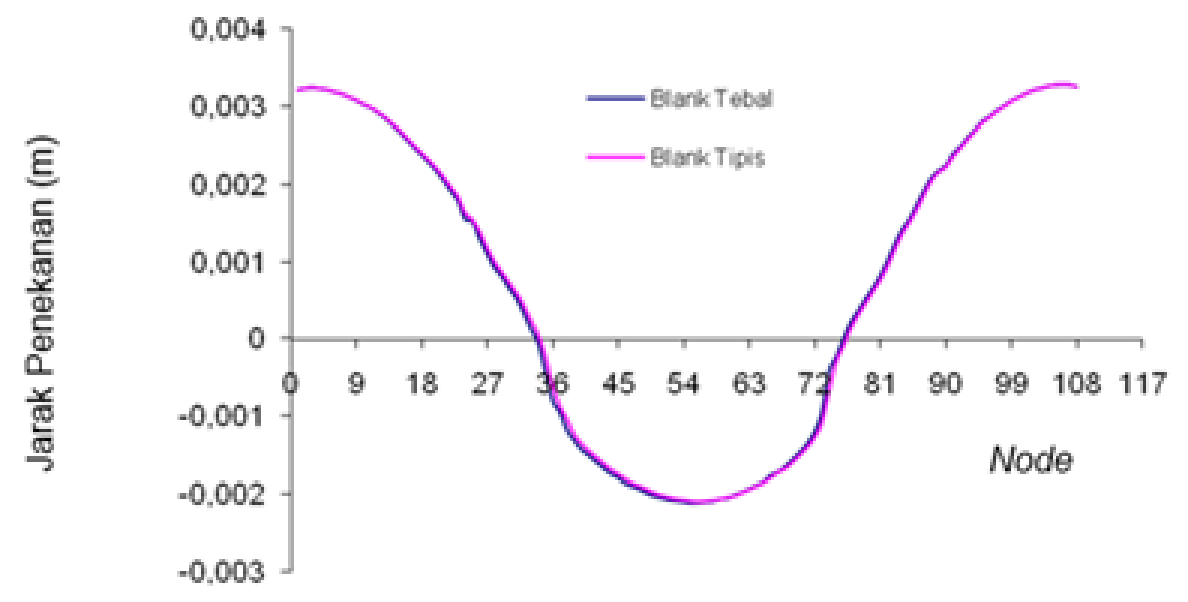

Gambar 17. Penyimpangan lajur las (Weld movement) pada pelat tebal dan pelat tipis

Dari grafik di atas, dapat diketahui bahwa pergerakan lajur las (weld displacement) mengalir dari pelat dengan ketebalan $1 \mathrm{~mm}$ menuju ketebalan $0,8 \mathrm{~mm}$. Welding displacement terbesar terjadi pada titik 3 yang mencapai 3,24 mm dan titik 107 yang mencapai 3,27 mm.

\section{KESIMPULAN}

1. Pada kedua pelat tebal dan pelat tipis, hasil simulasi menunjukkan kecenderungan yang sama, yaitu bahwa springback terbesar terjadi pada bagian penampang samping, sedangkan springback terkecil terjadi pada bagian bawah.

2. Pergerakan lajur las (weld movement) mengalir dari pelat dengan ketebalan $1 \mathrm{~mm}$ menuju ketebalan $0,8 \mathrm{~mm}$, hal ini terjadi karena tegangan mengalir menuju pada pelat yang lebih tipis.

\section{DAFTAR PUSTAKA}

[1] Ahmad Hasnan. S., 2006. Mengenal Proses Deep Drawing. Jakarta

[2] Andy. P., 2001. Tailor Welded Blank Applications And Manufacturing. Nort America

[3] Marciniak, Z., et.al.,2002., Mechanics of Sheet Metal Formimg, Butterworth Heinemann, London.

[4] ABAQUS Theory Manual, 2003. 